\title{
In Situ-Generated Oxide in Sn-Doped Nickel Phosphide Enables Ultrafast Oxygen Evolution
}

\author{
Tofik Ahmed Shifa,* Khabib Yusupov, Getachew Solomon, Alessandro Gradone, Raffaello Mazzaro, \\ Elti Cattaruzza, and Alberto Vomiero*
}

Cite This: ACS Catal. 2021, 11, 4520-4529

Read Online

\section{ACCESS | Lill Metrics \& More | 回 Article Recommendations ｜（） Supporting Information}

ABSTRACT: Water splitting is considered one of the most promising approaches to power the globe without the risk of environmental pollution. The oxygen evolution reaction (OER) is even more challenging because the generation of only one oxygen molecule involves the transfer of four $\mathrm{e}^{-}$and removal of four $\mathrm{H}^{+}$ions from water. Thus, developing highly efficient catalysts to meet industrial requirements remains a focus of attention. Herein, the prominent role of $\mathrm{Sn}$ in accelerating the electron transfer kinetics of $\mathrm{Ni}_{5} \mathrm{P}_{4}$ nanosheets in OER is reported. The post catalytic survey elucidates that the electrochemically induced $\mathrm{Ni}-\mathrm{Sn}$ oxides at the vicinity of phosphides are responsible for the observed catalytic activity, delivering current densities of 10 , 30 , and $100 \mathrm{~mA} \mathrm{~cm}^{-2}$ at overpotentials of only $173 \pm 5.2,200 \pm 7.4$, and $310 \pm$ $5.5 \mathrm{mV}$, respectively. The density functional theory calculation also supports the experimental findings from the basis of the difference observed in density of

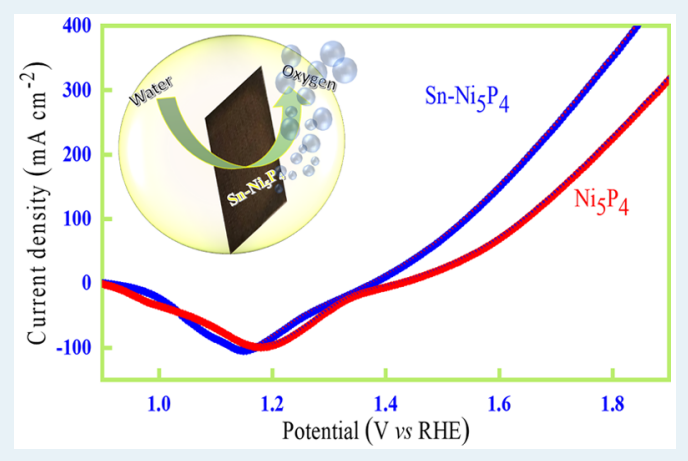
states at the Fermi level in the presence/absence of $\mathrm{Sn}$. This work underscores the role of $\mathrm{Sn}$ in OER and opens a promising avenue toward practical implementation of hydrogen production through water splitting and other catalytic reactions.

KEYWORDS: in situ-generated oxides, $\mathrm{Ni}_{5} \mathrm{P}_{4}$ nanosheets, $\mathrm{Sn}$ doping, phosphide vicinity, OER

\section{INTRODUCTION}

The development of reliable and affordable energy sources is a key step in the quest to achieve the sustainable development goals (SDGs) set by the United Nations (UN). ${ }^{1}$ Water splitting is considered as an important pathway to produce spotless energy and substantially increase the share of renewable energy source in the global energy supplies. ${ }^{2-4}$ However, the oxygen evolution reaction (OER) counterpart with sluggish kinetics has remained a grand bottleneck to realize efficient water-splitting technologies meeting the desired goals. Even the conventionally accepted benchmark catalysts such as $\mathrm{IrO}_{2}$ and $\mathrm{RuO}_{2}$ are not that satisfactory in catalyzing OER, not to mention their scarcity and high cost. ${ }^{5}$ OER also plays a pivotal role in the production of carbon fuels ${ }^{6}$ and achieving rechargeable metal-air batteries, ${ }^{7}$ in addition to splitting water. This necessitates the exploration of catalysts driving OER at a lower overpotential and faster kinetics. In this regard, metal oxides/double-layer hydroxides have been acknowledged for their promising performances in catalyzing OER $^{8,9}$ However, they are challenged by their intrinsically poor conductivity, impeding the rate of electron transfer and thereby jeopardizing the entire catalytic activity. ${ }^{10}$ Owing to their higher conductivity, metal chalcogenides/phosphides are excellent alternatives to metal oxides. ${ }^{11,12}$ Of particular note is that phosphides play a paramount role in the catalysis of watersplitting reactions. For instance, Pan et al. ${ }^{13}$ evaluated the catalytic activities of various nickel phosphides and reported that it increases in the order of increasing phosphorous content $\left(\mathrm{Ni}_{5} \mathrm{P}_{4}>\mathrm{Ni}_{2} \mathrm{P}>\mathrm{Ni}_{12} \mathrm{P}_{5}\right)$. Nowadays, various experimental evidence deduce that metal phosphides/chalcogenides are not the true catalysts in OER. ${ }^{14-16}$ Their surface undergoes an electrochemical transformation into the corresponding oxides/ hydroxides, which eventually play the catalysis role. Therefore, these materials are strictly precatalysts. The oxides/hydroxides moieties formed in this case are apparently more catalytically active than the pristine oxides as they are formed in the vicinity of conductive platforms.

Alloying has long been considered as an effective method of introducing new features on the catalyst toward optimizing the energetics and kinetics for the desired reaction. ${ }^{17-24}$ When it comes to phosphides, the in situ-formed surface oxides/ hydroxides will have a conducive system to favorably perpetrate the synergism between multimetals for enhanced catalysis. Based on these premises, bimetallic phosphides such as $\mathrm{Ni}-\mathrm{Fe}-\mathrm{P},{ }^{14,25-27} \mathrm{Co}-\mathrm{Fe}-\mathrm{P},{ }^{15} \mathrm{Mn}-\mathrm{Fe}-\mathrm{P},{ }^{16} \mathrm{Ni}-\mathrm{Co}-$

Received: February 1, 2021

Revised: March 17, 2021

Published: March 29, 2021 

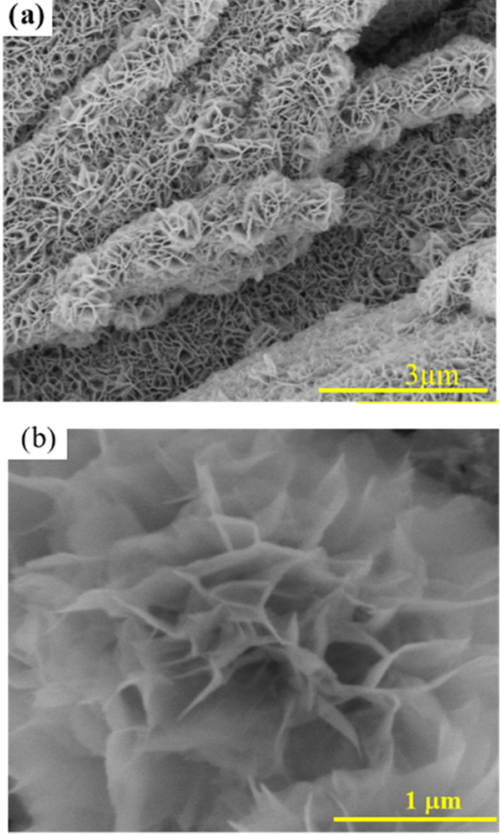

(c)
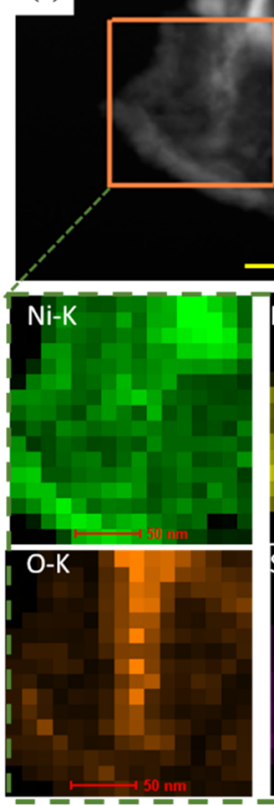
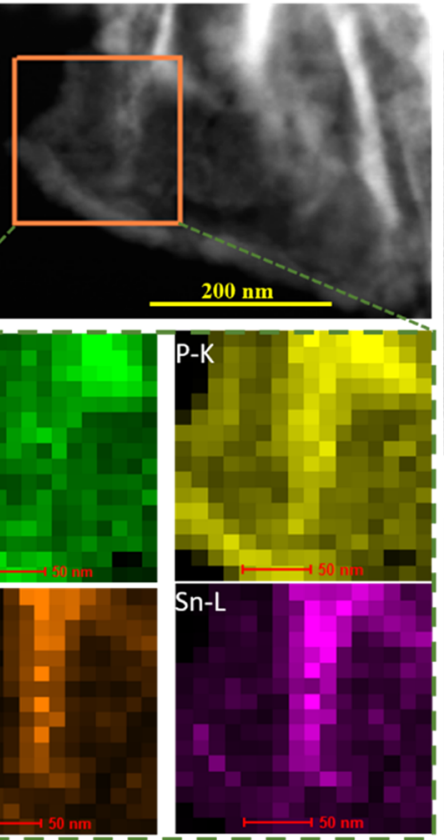

(d)
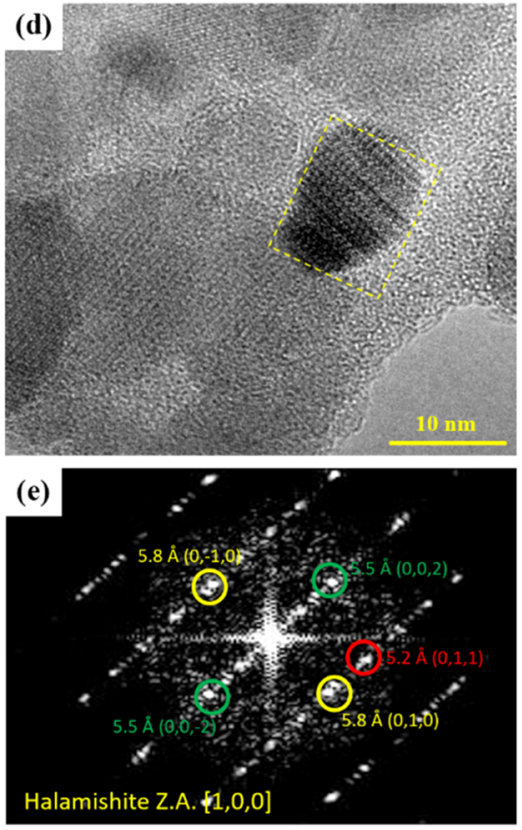

Figure 1. Morphology and elemental distribution: (a,b) Scanning electron microscopy images of SnNiP. (c) STEM-HAADF micrograph with relative EDS mapping of the highlighted area (orange rectangle) for $\mathrm{Ni}$ (green), Sn (purple), P (yellow), and O (orange). (d) High-resolution transmission electron microscopy image of SnNiP and (e) Fourier transform pattern of the marked region in (b).

$\mathrm{P}{ }^{28-31} \mathrm{Al}-\mathrm{Ni}-\mathrm{P},{ }^{32}$ and $\mathrm{Ru}-\mathrm{Ni}_{5} \mathrm{P}_{4}^{33}$ have been investigated and promising results were communicated.

In this work, we describe the active role of $\mathrm{Sn}$ in tackling the sluggish kinetics of OER. The most compelling feature in Snbased catalysis is that the oxygen-bound intermediates interact more favorably on the Sn surface. ${ }^{34-36}$ Thus, promising results were communicated via utilizing Sn-based materials in water splitting. ${ }^{37-39}$ Despite such remarkable etiquettes of $\mathrm{Sn}$, its role in enhancing the OER activity of metal phosphides has been barely studied. We alloyed $\mathrm{Sn}$ in the nickel oxyhydroxide nanosheets and phosphorized the content in a chemical vapor deposition (CVD) setup to synthesize a Sn-doped $\mathrm{Ni}_{5} \mathrm{P}_{4}$ precatalyst. Our post catalytic characterizations reveal that the surface is completely transformed into $\mathrm{Sn}_{x} \mathrm{NiO}$, demonstrating that the catalytic activity took place as a result of the in situ-formed oxide. The presence of $\mathrm{Sn}$ and the in situgenerated oxide collectively assist the increase of density of states (DOS) at the Fermi level and makes the d-states closer to the Fermi level. Through the combination of experimental and computational findings, we demonstrated that the in situgenerated $\mathrm{Sn}-\mathrm{Ni}$ oxides at the phosphide surrounding exhibit superior kinetics for the catalysis of OER.

\section{RESULTS AND DISCUSSION}

Vertically oriented nanosheets of tin-doped nickel oxyhydroxide $\left(\mathrm{Sn}_{-} \mathrm{Ni}_{2} \mathrm{O}_{3} \mathrm{H}\right)$ were first prepared through a hydrothermal method on a carbon fiber (CF) substrate (Figure $\mathrm{S} 1 \mathrm{a}, \mathrm{b})$. The as-obtained product was then phosphorized in CVD to yield $\mathrm{Sn}$-doped $\mathrm{Ni}_{5} \mathrm{P}_{4}$. For comparison, the undoped $\mathrm{Ni}_{5} \mathrm{P}_{4}$ was also synthesized through the same reaction but without the addition of $\mathrm{Sn}$ (details are given in the Experimental Details section). The measurements were made based on these three samples $\left(\mathrm{Sn}-\mathrm{Ni}_{2} \mathrm{O}_{3} \mathrm{H}, \mathrm{Sn}\right.$-doped $\mathrm{Ni}_{5} \mathrm{P}_{4}$, and $\left.\mathrm{Ni}_{5} \mathrm{P}_{4}\right)$ to unequivocally understand the role of the electrochemically induced oxide on OER. The scanning electron microscopy (SEM) images in Figure 1a,b display the flower-like morphology of the phosphorized product, composed by vertically assembled nanosheets. The morphology of the material is preserved after optimum Sn doping (Figure S1c). Further details on the nanoscale morphology and structure were examined through transmission electron microscopy (TEM). As can be seen in Figure S2, the basal plane of the nanosheets contains small nanoparticles whose diameter ranges from 5 to $20 \mathrm{~nm}$. This accounts for the roughness of the phosphorized product that would, in turn, assist the exposure of active sites for enhanced kinetics. ${ }^{40,41}$ The elemental composition of the sample was measured by energy-dispersive X-ray spectroscopy (EDS), revealing the presence of $\mathrm{Sn}, \mathrm{Ni}$, and $\mathrm{P}$ with atomic ratios $\mathrm{P}$ to $\mathrm{Ni}$ and $\mathrm{Sn}$ to $\mathrm{Ni}$ of 0.8 and 0.06 , respectively (Figure S3). These elements are homogeneously distributed in the nanosheets, as evidenced by the EDS mapping in Figure 1c, resulting from the highlighted area on the scanning transmission electron microscopy-high-angle annular dark-field (STEM-HAADF) micrograph (more EDS mapping is provided in the Supporting Information Figure S4). A slightly increased $\mathrm{Sn}$ and a nonnegligible $\mathrm{O}$ content are observed on strained areas such as wrinkles and edges, where the product might be partially oxidized due to environmental exposure. Moreover, the X-ray diffraction (XRD) pattern in Figure S5 illustrates that the crystal structure of the phosphorized product fits the major standard peaks of Halamishite, $\mathrm{Ni}_{5} \mathrm{P}_{4}$ (PDF\#18-0883), agreeing with the elemental ratio observed in EDS. In general, the XRD patterns show low intensity and broad diffraction peaks. The broad peak at around $2 \theta=25^{\circ}$ originated from the CF substrate. The other peaks are slightly shifted and/or diminished in intensity, which can be associated with lattice distortion because of doping with another atom $(\mathrm{Sn})$. The difference in atomic radii ( $\mathrm{Sn}$ has a larger atomic radius as compared to $\mathrm{Ni}$ ) could give rise to such lattice distortion. Figure S6a shows that the effect is more apparent with increasing concentration of $\mathrm{Sn}$. This can be corroborated by 

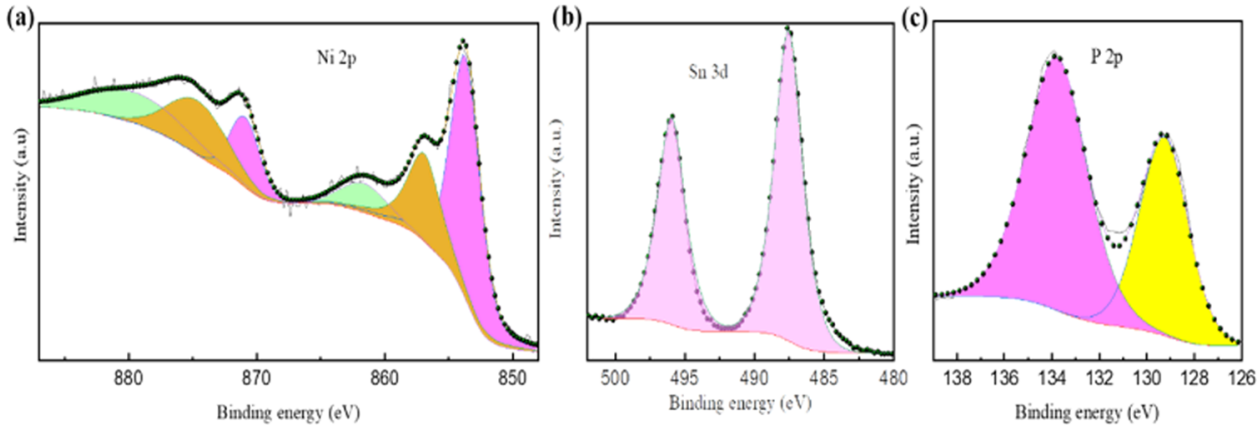

Figure 2. High-resolution X-ray photoelectron spectra in SnNiP: (a) Ni 2p, (b) Sn 3d, and (c) P 2p.

(a)

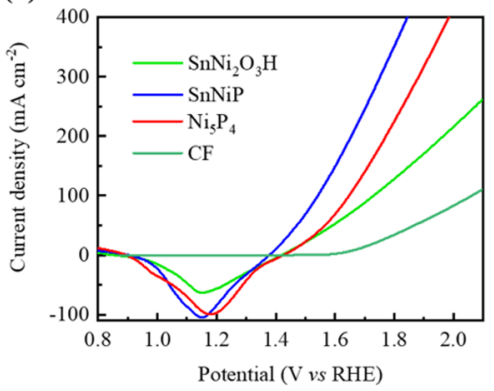

(d)

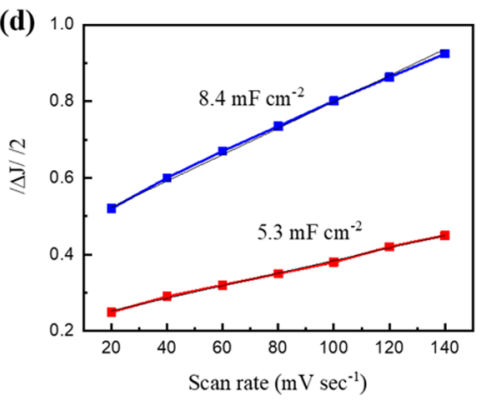

(b)

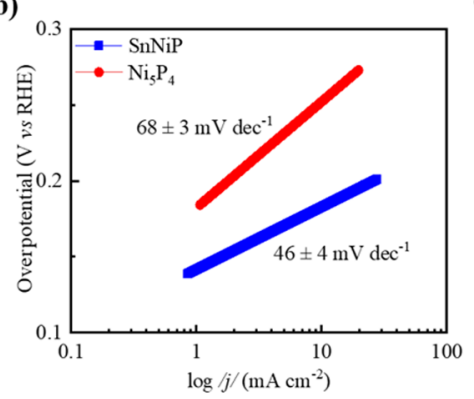

(c)

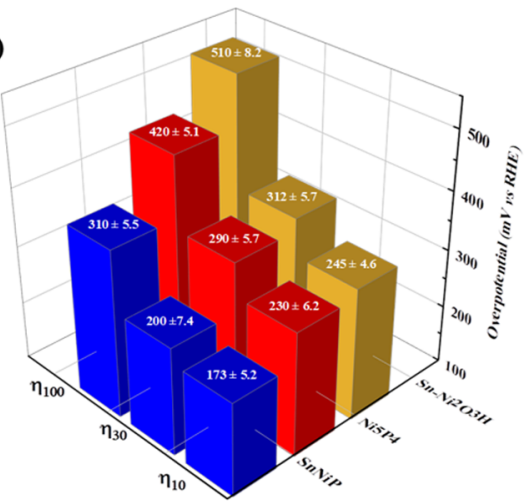

(e)

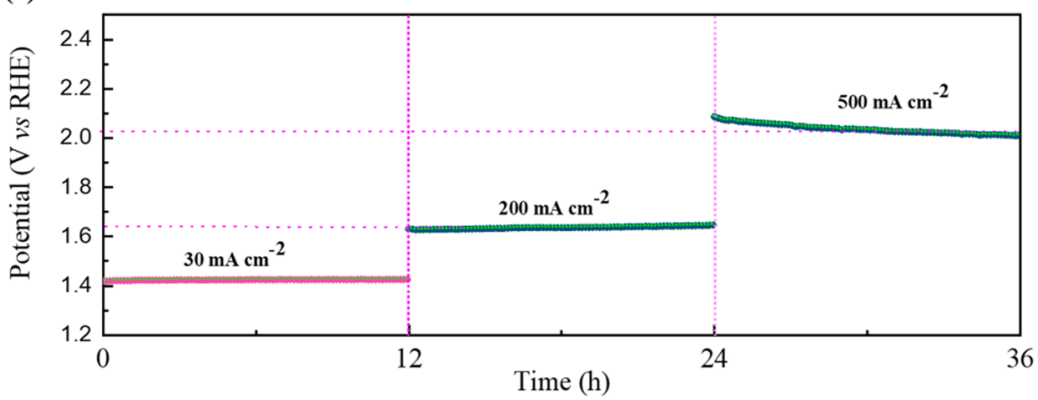

Figure 3. Electrocatalytic oxygen evolution reaction activity: (a) OER polarization curves from the linear sweep voltammetry. (b) Tafel plots for $\mathrm{SnNiP}$ and $\mathrm{Ni}_{5} \mathrm{P}_{4}$ extracted from the polarization curves in (a). (c) Comparison of overpotentials for $\eta 10$, $\eta 30$, and $\eta 100$. (d) Double-layer capacitance $\left(C_{\mathrm{dl}}\right)$ measurements of $\mathrm{SnNiP}$ and $\mathrm{Ni}_{5} \mathrm{P}_{4}$ catalysts. (e) Chronopotentiometric run of SnNiP for the long-term durability test at 30, 200; and $500 \mathrm{~mA} / \mathrm{cm}^{2}$.

the SEM images (Figure S6b-e) showing the appearance of spherical aggregates on the nanosheets at $4 \%$ at Sn making the structure disordered and nonhomogeneous. Similar observations have been made for the case of Mn-doped $\mathrm{Fe}_{2} \mathrm{P} .{ }^{16}$ Further insight into the crystallographic structure of our sample was gained from high-resolution transmission electron microscopy (HRTEM) substantiating clearly distinguishable crystal fringes, as reported in Figure 1d. The fast Fourier transformation (FFT) of the marked region in Figure 1d is illustrated in Figure 1e. The highlighted crystal fringes were assigned to (002), (011), and (010) lattice planes. The pattern can be indexed to the Halamishite phase, specifically on the $[1,0,0]$ zone axis. These results, in accordance with XRD and EDS observations, indicate that the phosphorization of the oxide precursor led to the formation of $\mathrm{Sn}$-doped $\mathrm{Ni}_{5} \mathrm{P}_{4}$ (hereafter, $\mathrm{SnNiP}$ ).

The surface chemical composition and oxidation states of the components in the product were unveiled by X-ray photoelectron spectroscopy (XPS). After doping, we have observed only a slight change in the BE of XPS peaks that may convey the alteration on the electronic structure of the pristine $\mathrm{Ni}_{5} \mathrm{P}_{4}$. Figure 2a shows a deconvoluted high-resolution XPS spectrum of $\mathrm{Ni} 2 \mathrm{p}$ in $\mathrm{SnNiP}$ : due to the well-known complexity of the Ni $2 p$ band structure, we also simulated the shake-up part to obtain a reliable fit. It imparts that nickel in the sample is present as $\mathrm{Ni}^{2+}\left(\mathrm{Ni} 2 \mathrm{p}_{3 / 2}\right.$ band centered at $853.7 \mathrm{eV}$, spinorbit splitting of $17.2 \mathrm{eV}$ ) and possibly $\mathrm{Ni}^{3+}\left(\mathrm{Ni} 2 \mathrm{p}_{3 / 2}\right.$ band centered at $856.9 \mathrm{eV}$, spin-orbit splitting of $17.7 \mathrm{eV})$. A slight shift $(0.3 \mathrm{eV})$ in the binding energy is present, as compared to the Ni $2 p$ spectrum in the pristine compound (Figure S7). This may be associated with the electron transfer between the $\mathrm{Sn}$ species and that of $\mathrm{Ni}$ in the $\mathrm{Ni}_{5} \mathrm{P}_{4}$ matrix. The XPS spectrum of $\mathrm{Sn}$ evidences the existence of one single $\mathrm{Sn} 3 \mathrm{~d}$ signal due to tin oxides and/or tin phosphites: the $\mathrm{Sn} 3 \mathrm{~d}_{5 / 2}$ band is centered at binding energy (BE) of $487.6 \mathrm{eV}$, with a spin-orbit splitting of $8.4 \mathrm{eV}$ (Figure 2b). Likewise, the presence and the chemical nature of phosphorus is deemed from the collected XPS spectra, as shown in Figure 2c. The P 
$2 \mathrm{p} 3 / 2+1 / 2$ band is made by two components: the first is centered at $\mathrm{BE}$ of $129.0 \mathrm{eV}$ and attributable to phosphorus in metal phosphide compounds (Ni-P and $\mathrm{Sn}-\mathrm{P})$. This peak is shifted $(0.4 \mathrm{eV})$ to lower binding energy positions compared to the phosphorus in the pristine sample, substantiating the electron transfer from the metals to phosphorus. The other component is peaked at $\mathrm{BE}$ of $133.5 \mathrm{eV}$ and related to metal phosphites $\left(-\mathrm{PO}_{4}{ }^{3-}\right)$ that appear due to superficial oxidation once the sample is exposed to air. ${ }^{14}$ In our case, both $\mathrm{Ni}$ and Sn could contribute to this part. Quantitatively, around 14\% at $\mathrm{P}$ along with $11 \%$ at $\mathrm{Ni}$ and $4 \%$ at $\mathrm{Sn}$ accounts for surface oxidation induced by air exposure.

To gain insight into the catalytic performance of the synthesized material and the other control samples, we measured the electrocatalytic activity in a three-electrode system (in $1 \mathrm{M} \mathrm{KOH}$ ), wherein a saturated calomel electrode (SCE), a graphite rod, and the samples under investigation served as reference, counter, and working electrodes, respectively. In situ electrochemical activation was employed through CV tests by varying the number of applied cycles (10, $25,50,75$, and 100) to optimize the number of cycles required for surface activation. As shown in Figure S9a, 50 cycles are optimum for activation and hence the analysis made in this study is after activation via CV runs of 50 cycles. The full CV scan after activation is depicted in Figure S10, illustrating the redox peaks. The polarization curve in Figure $3 \mathrm{a}$ reveals a negligible catalytic activity for the bare carbon fiber, suggesting that the catalytic activity recorded for the rest of the samples comes solely from the synthesized materials on the carbon fiber. The $\mathrm{Sn}-\mathrm{Ni}_{2} \mathrm{O}_{3} \mathrm{H}$ and the undoped $\mathrm{Ni}_{5} \mathrm{P}_{4}$ display only modest activity toward OER. As expected, the best catalytic activity toward water oxidation is recorded for the $\mathrm{SnNiP}$ sample. We also tested the relationship between the level of the Sn dopant in $\mathrm{Ni}_{5} \mathrm{P}_{4}$ and the final OER activity (Figure S9b). The Sn content plays a critical role. In this study, we observed that $3 \%$ at $\mathrm{Sn}$ is the optimum doping level. The concentration of $\mathrm{Sn}$ beyond the optimum decreases the catalytic activity as it deforms the lattice and suppresses the exposure of catalytic active sites. The presence of Sn may play a paramount role in perturbing the electronic structure of the nickel phosphide matrix toward optimizing the surface for favorable kinetics and energetics in the oxygen evolution reaction. Notably, the reaction kinetics is greatly facilitated after $\mathrm{Sn}$ incorporation, as evident from the smaller Tafel slope (Figure $3 b$ ) recorded for

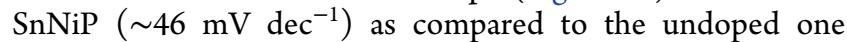

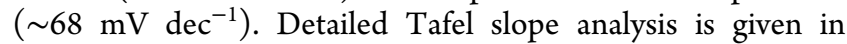
Figure S11. We further corroborated via chronoamperometry measurements, as this route eliminates capacitive current effects, allowing a more reliable analysis. ${ }^{42}$ The comparison of overpotentials recorded at specific current densities is depicted in Figure 3c. It is apparent that lowest overpotentials such as $173 \pm 5.2,200 \pm 7.4$, and $310 \pm 5.5 \mathrm{mV}$ are recorded for $\mathrm{SnNiP}$ catalysts for delivering current densities of 10,30 , and $100 \mathrm{~mA} \mathrm{~cm}^{-2}$, respectively. These potentials are the lowest (if not comparable) compared to the most recently reported $^{14-16,32,43-49}$ catalysts for water oxidation (Figure 4). We have also evaluated the electrochemically active surface area of the catalysts by calculating the double-layer capacitance $\left(C_{\mathrm{dl}}\right)$ as it estimates the electrochemically exposed active sites. For this, cyclic voltammetries at a nonfaradic region were run at various scan rates (Figure S12a,b), from which the differences of current densities as a function of scan rates were determined, as plotted in Figure $3 \mathrm{~d}$. The $C_{\mathrm{dl}}$ value of

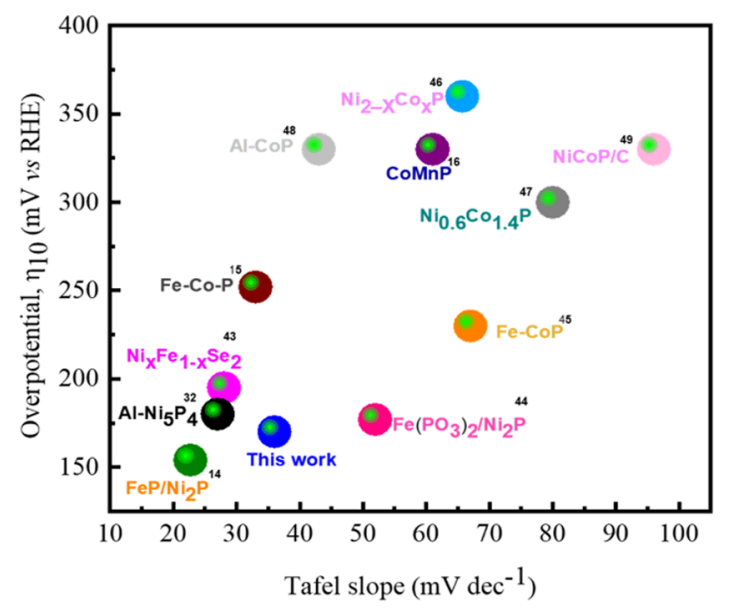

Figure 4. Comparison of the OER performances in $1 \mathrm{M} \mathrm{KOH}$ in terms of Tafel slopes and overpotentials required for driving current densities of $10 \mathrm{~mA} \mathrm{~cm}{ }^{-2}$.

SnNiP $\left(8.4 \mathrm{mF} \mathrm{cm}^{-2}\right)$ is found to be higher than that of $\mathrm{Ni}_{5} \mathrm{P}_{4}$ $\left(5.3 \mathrm{mF} \mathrm{cm} \mathrm{cm}^{-2}\right)$. This result demonstrates that $\mathrm{Sn}$ doping triggers the exposure of more active sites on the surface. In fact, dopant-host interaction in an alkaline condition has its own feature to contribute to a wider geometrical space for the charging/discharging; an analogous observation was made by Al-doped $\mathrm{Ni}_{5} \mathrm{P}_{4}{ }^{3}$

Increasing intrinsic activity is considered as a vital route toward realizing the scaling-up of water-splitting catalysts. It guarantees direct increase in electrode activity without the problem of mass-transport issues arising from high catalyst loadings. ${ }^{50} \mathrm{Sn}$ doping can also alter the intrinsic properties of $\mathrm{Ni}_{5} \mathrm{P}_{4}$. To prove this, we evaluated the turnover frequency (TOF) for each active site using electrochemical methods (Figure S13). Accordingly, the SnNiP sample outperforms the undoped catalysts, exhibiting $\sim 2.5$ times higher TOF than $\mathrm{Ni}_{5} \mathrm{P}_{4}$ at an overpotential of $350 \mathrm{mV}$. Moreover, after normalizing the polarization curves by the electrochemical active surface area, (ECSA) SnNiP still exhibits better catalytic activity (Figure S14) further portraying the intrinsically enhanced performance in OER catalysis. Meanwhile, the charge-transfer resistances were analyzed by the Nyquist plots (Figure S15a). The smaller semicircle in the electrochemical impedance spectra (EIS) of the $\mathrm{SnNiP}$ catalyst evidences the enhanced conductivity, whose charge-transfer resistance $\left(R_{\mathrm{ct}}\right)$ is calculated to be $16 \Omega$, as compared to the pristine $\mathrm{Ni}_{5} \mathrm{P}_{4}\left(R_{\mathrm{ct}}\right.$ $=233 \Omega$ ). The OER catalysis still exhibit excellent kinetics after the stability test (Figure S15b). Together, these results suggest that doping of $\mathrm{Sn}$ intrinsically boosts the catalytic activity of $\mathrm{Ni}_{5} \mathrm{P}_{4}$. Our computational findings (described below) also verify this hypothesis based on the increased density of states around the Fermi level as a result of Sn doping.

It is well recognized that OER catalyst stability is a bottleneck in realizing scalable water-splitting technology. We conducted chronopotentiometry at various current densities $\left(30,200\right.$, and $\left.500 \mathrm{~mA} \mathrm{~cm}{ }^{-2}\right)$ for a total of $36 \mathrm{~h}$ (12 at each current density). As can be seen from Figure $3 \mathrm{e}, \mathrm{SnNiP}$ demonstrates very good stability with only minor degradation over long-term testing. It retains $99.5,98.78$, and $99.4 \%$ activity at 30,200 , and $500 \mathrm{~mA} \mathrm{~cm}{ }^{-2}$, respectively. The polarization curve after stability (Figure S16) is also nearly identical to the original one, further solidifying the stable activity in water 
a)

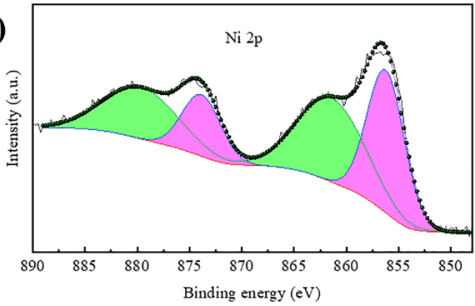

d)

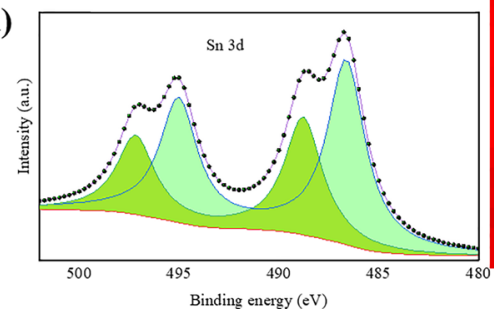

b)
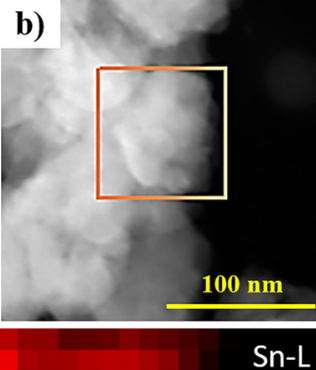

Sn-L

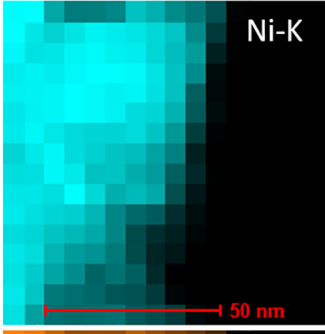

O-K
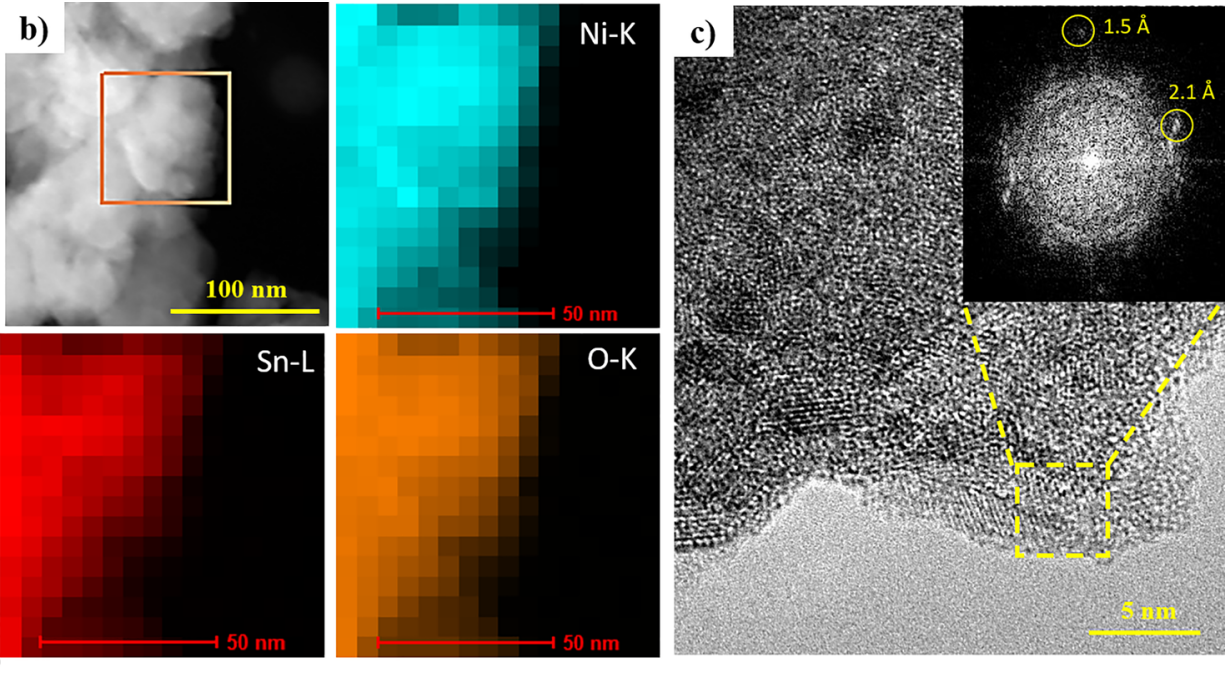

Figure 5. Post catalytic activity characterizations: high-resolution $x$-ray photoelectron spectra of Ni 2p (a) and Sn $3 \mathrm{~d}$ (d) in the SnNiP sample after OER experiments. (b) STEM-HAADF micrograph and relative EDS mapping for Ni, Sn, and O. (c) HRTEM micrograph of the edge of a nanosheet and relative FFT.

oxidation. The constant potential recorded at each respective current density implies the mechanical robustness during mass transport in electrolysis.

To gain a clear understanding on the origin of the observed catalytic activity, we conducted post OER characterizations. The XPS spectra in Figure 5a,b uncover that the catalyst has undergone a remarkable change on the surface chemistry of $\mathrm{SnNiP}$. The same observation has been made for the pristine $\mathrm{Ni}_{5} \mathrm{P}_{4}$ (Figure S7). It is noteworthy that other reports on OER catalysis also support this phenomenon. ${ }^{14-16,51}$ Especially, the surface of phosphides is prone to oxidation during catalysis and we are attributing the enhanced catalytic activity to such in situ-formed oxide at the vicinity of phosphides. Accordingly, nickel shows a single component of the $\mathrm{Ni} 2 \mathrm{p}_{3 / 2}$ band centered at a $\mathrm{BE}$ value of $856.2 \mathrm{eV}$, related to $\mathrm{Ni}$ oxide/hydroxide. ${ }^{52}$ Apart from the change in the chemical state, we have also witnessed a significant amount of $\mathrm{K}$ (from the electrolyte, $1 \mathrm{M}$ $\mathrm{KOH}$ ) at the sample surface and dissolution of tin and phosphorus from the surface of the catalyst. This phenomenon of leaching (metal/nonmetal dissolution) leaves behind a more active and conductive platform for catalysis, recapitulating previous studies. $^{32,53}$ The presence of tin and phosphorus on the first few $\mathrm{nm}$ of the surface is near the detection limit of XPS $(\sim 0.1 \%)$. Figure $5 b$ illustrates the high-resolution XPS spectra of the remaining tin on the catalyst after OER is recorded with a very long acquisition time. Beside the $S n 3 d_{5 / 2}$ peak centered at $\mathrm{BE}$ of $486.6 \mathrm{eV}(8.4 \mathrm{eV}$ of spin-orbit splitting) owing to the formation of elemental $\mathrm{Sn}$ or $\mathrm{Sn}^{2+}$ species, ${ }^{54}$ we have also detected an additional component centered at $\mathrm{BE}$ of $488.8 \mathrm{eV}$ (same spin-orbit splitting), possibly corresponding to the presence of $\mathrm{Sn}^{4+}$. These values are larger than those usually observed from the $S n 3 d_{5 / 2}$ band, likely due to some charge-transfer mechanisms. Post catalytic XPS analysis for phosphorus indicates that the amount of $\mathrm{P}$ on the surface is near the detection limit (Figure S17), substantiating the fact that the catalytic activity is entirely due to the surface oxide of $\mathrm{Sn} / \mathrm{Ni}$ metals. This dramatic surface chemical change during water oxidation is further supported by HRTEM observation elucidated in Figure 5c. The crystal fringes and the associated FFT image corroborate the existence of $\mathrm{NiO}$. The crystal domain is reduced to few $\mathrm{nm}$ because of its amorphous feature following the low-temperature electrochemically induced oxidation process. Moreover, the elemental mapping (Figure 5b) of high-angle annular dark-field scanning transmission electron microscopy (HAADF-STEM) solidifies the existence of $\mathrm{Ni}, \mathrm{Sn}$, and $\mathrm{O}$ on the catalyst with a homogeneous distribution such that the pattern of $\mathrm{O}$ goes along with $\mathrm{Ni}$ and $\mathrm{Sn}$, further evidencing the formation of metal oxides. To further verify our hypothesis, we carried out Raman spectroscopic characterization (Figure S18) before and after the OER test to see what new features could come out in the support of the in situ-formed new chemical species. We did not find any detectable Raman vibration modes upon $531 \mathrm{~nm}$ laser excitation for the SnNiP sample before the OER test.

Interestingly, new peaks appeared at around 502 and 1061 $\mathrm{cm}^{-1}$ that are attributed to the first-order longitudinal optical (LO) phonon and a combination of two transverse optical (2TO)/2LO modes of $\mathrm{NiO}$, respectively, after the OER test. $^{55,56}$ In fact, the electrochemical transformation during OER has been reported for various kinds of chalcogenides 43,57 and phosphides ${ }^{11,14}$ during OER. It is suggested that the interface between metal phosphide/chalcogenides and metal oxide/hydroxide assists the charge-carrier transport from the interior to the exterior oxide/hydroxide species. ${ }^{58}$ What is even more important here is the fact that Sn plays a paramount role in intensifying the density of electronic states at the Fermi level, thereby favoring the kinetics of water oxidation on $\mathrm{NiO}$ in which the phosphate vicinity provides a conductive platform.

To get further insight into the mechanism of the enhanced OER activity, we conducted density functional theory (DFT) calculation. The perfect crystal structures of $\mathrm{Ni}_{5} \mathrm{P}_{4}, \mathrm{Ni}_{5}(\mathrm{P} / \mathrm{O})_{4}$, and $\mathrm{SnNi}(\mathrm{P} / \mathrm{O})_{4}$ (Figure 6) were constructed based on the experimental results of XRD/HRTEM. The DFT calculation was performed on the (002) crystal plane to study the effect of oxidization of the top layer and the Sn doping $(3.75 \%$ at $\mathrm{Sn}$ was considered) on the electronic structure at the atomic level. According to the performed calculations, the substitution of the phosphorus atoms with oxygen during the oxidation process at the top layer shifts the energy levels toward the 
(a)

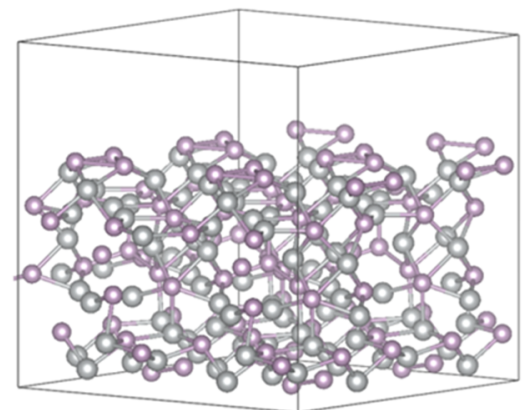

(b)

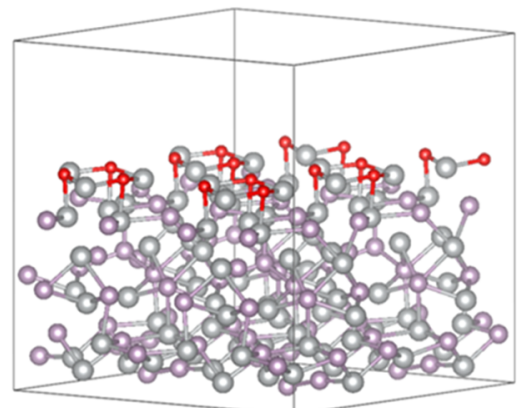

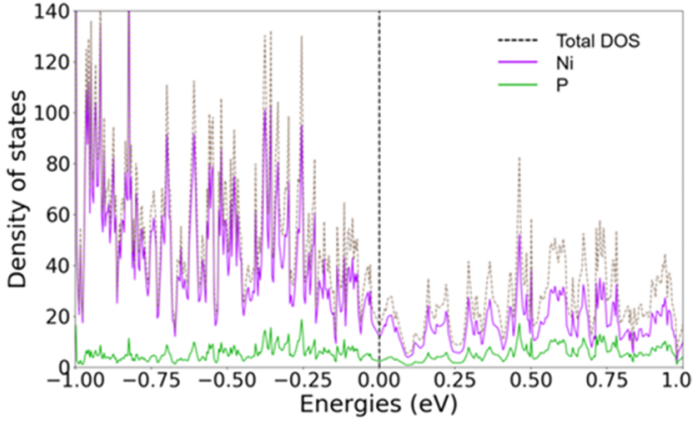

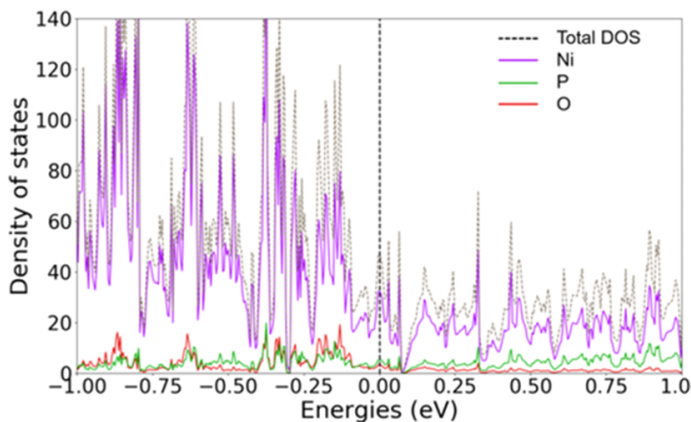

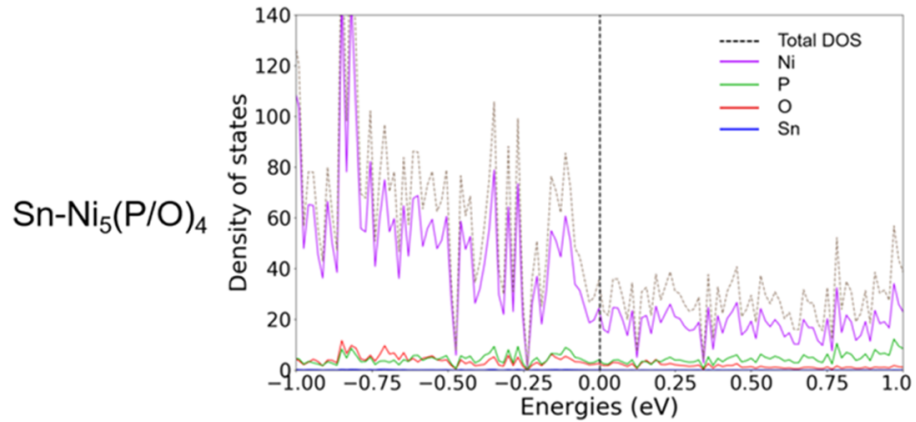

(c)

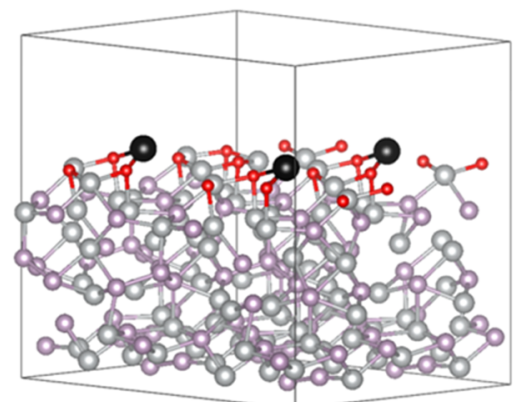

Figure 6. Crystal structure and corresponding density of states for (a) pure $\mathrm{Ni}_{5} \mathrm{P}_{4}$, (b) oxidized system $\mathrm{Ni}_{5}(\mathrm{P} / \mathrm{O})_{4}$, and (c) Sn-doped oxidized system $\mathrm{Sn}_{-} \mathrm{Ni}_{5}(\mathrm{P} / \mathrm{O})_{4}$. Nickel atoms are marked with purple, phosphorous atoms with gray, oxygen atoms with red, and $\mathrm{Sn}$ atoms with a bigger atomic radius with black color.

Fermi level compared to the nonoxidized $\mathrm{Ni}_{5} \mathrm{P}_{4}$, which could point to a favorable system for water oxidation. The doping with $\mathrm{Sn}$ atoms, which are replacing $\mathrm{Ni}$ atoms, leads to the increased density of energy levels at the Fermi level, suggesting a conducive platform for catalytic activity. The increased density of states (DOS) at the Fermi level indicates that the catalytic reaction can be affected directly by the large increase in the charge-carrier density that should lead to an improved OER process. Additionally, the increased number of energy levels near the Fermi level is supposed to boost the chargetransfer kinetics of the system, which has been experimentally proved through the EIS measurements. Further increase of the Sn concentration within the top layer of the crystal structure results in unstable behavior, i.e., the system is no longer stable and the top layer shows a tendency of decomposition. This tendency is reflected by the elongation of the bond between $\mathrm{Sn}$ elements and near atoms. For example, the distance between $\mathrm{Sn}$ and near oxygen atoms (Figure S19) at the top layer for different percentages of $\mathrm{Sn}$ is different, $2.048 \AA$ (for $16 \% \mathrm{Sn}$ ) and $2.066 \AA$ (for $33 \% \mathrm{Sn}$ ). A further increase in the concentration leads to the state where the calculations cannot converge and reach the energy ground state.

\section{CONCLUSIONS}

In summary, we presented a facile method for the synthesis of Sn-doped $\mathrm{Ni}_{5} \mathrm{P}_{4}$ that exhibits excellent catalytic activity toward water oxidation in an alkaline medium. The presence of Sn, confirmed by EDS and XPS analysis, increases the density of states at the Fermi level, accelerating the charge-transfer kinetics across the electrode-electrolyte interface. Indeed, the catalyst delivered a current density of $10 \mathrm{~mA} \mathrm{~cm}{ }^{-2}$ at an overpotential as low as $173 \pm 5.2 \mathrm{mV}$ vs RHE and with a record small Tafel slope $\left(\sim 46 \mathrm{mV} \mathrm{dec}^{-1}\right)$. Our finding points out that the in situ-formed oxide moieties play an active role in catalysis, in which the phosphide vicinity also contributes its part. Moreover, the oxygen-bound intermediates interact more favorably on the $\mathrm{SnNiO}$ surface as compared to the undoped ones, which can contribute to the enhanced OER catalysis. 
This work demonstrates the prominent role of $\mathrm{Sn}$ in water splitting and paves the way for the subsequent investigations in the quest for breakthroughs in many energy conversion/ storage techniques such as regenerative fuel cells and rechargeable metal-air batteries.

\section{EXPERIMENTAL DETAILS}

Synthesis of the Oxide Precursor. A carbon fiber (CF) substrate was first cut into an appropriate dimension and sonicated in ethanol, acetone, and distilled water. To prepare the precursors solution, $1.7 \mathrm{~g}$ of $\mathrm{Ni}\left(\mathrm{NO}_{3}\right)_{3} \cdot 6 \mathrm{H}_{2} \mathrm{O}$ and $0.3 \mathrm{~g}$ of $\mathrm{SnCl}_{2} \cdot 2 \mathrm{H}_{2} \mathrm{O}$ were mixed well in $50 \mathrm{~mL}$ of ultrapure distilled water. To the obtained homogeneous solution, $0.9 \mathrm{~g}$ of urea and $0.2 \mathrm{~g}$ of $\mathrm{NH}_{4} \mathrm{~F}$ were added by stirring the entire content. The volume of the solution was made up to $100 \mathrm{~mL}$ by distilled water. Then, the solution was transferred to a Teflonlined stainless steel autoclave containing the cleaned CF substrate standing vertically. The whole content was then heated in an oven at $120{ }^{\circ} \mathrm{C}$ for $6 \mathrm{~h}$. The $\mathrm{CF}$ was then taken out, rinsed with ethanol/water, and dried in an oven at $60{ }^{\circ} \mathrm{C}$.

Phosphorization. The obtained metal oxyhydroxide precursor was placed in a chemical vapor deposition tube 3 $\mathrm{cm}$ away from $0.5 \mathrm{~g}$ of red phosphorus. The system was flushed with $\mathrm{Ar}$ gas three times and pumped into a vacuum level of lower than 1 pa. After deairing the system, the temperature of the red phosphorus zone was set to increase to $550{ }^{\circ} \mathrm{C}$ in 20 $\min$. The phosphorization reaction was run for $2 \mathrm{~h}$ with a 100 sccm Ar gas flow. Eventually, the system was allowed to naturally cool and the CF (onto which the material is now grown) was taken out to be used as an electrocatalyst without any treatment. The amount of $S n$ was varied to get the optimum dopant, which was accomplished via LSV run for the OER test.

Characterizations. The morphologies of the as-synthesized samples were investigated by field-emission scanning electron microscopy (FESEM), Magellan XHR 400L with a 5 $\mathrm{kV}$ electron beam. Nanoscale structural and compositional characterizations were performed on an FEI Tecnai F20 highresolution transmission electron microscope (HRTEM), equipped with a Schottky emitter operating at $200 \mathrm{kV}$. Elemental analysis was performed by energy-dispersive X-ray spectroscopy (EDS), either operated with single-point acquisition or coupled to scanning transmission electron microscopy (STEM-HAADF) to map elemental distribution. The PanAnalytical Empyrean XRD was employed to acquire the X-ray diffractogram using $\mathrm{Cu} k \alpha$ radiation. XPS spectra were collected using a Perkin Elmer spectrometer equipped with a non-monochromatized $\mathrm{Al}$ source $(1486.6 \mathrm{eV})$; surface charging was corrected by fixing the binding energy of the $\mathrm{C} 1 \mathrm{~s}$ signal from adventitious carbon at BE of $284.3 \mathrm{eV}$. Information about Raman spectra were collected using the Senterra Raman spectrometer from Bruker equipped with a $532 \mathrm{~nm}$ laser for excitation in the ambient environment.

Electrochemical Tests. The electrochemical tests were performed using the ModuLab XM ECS potentiostat (Solartron Instrument) in a three-electrode configuration in a $1 \mathrm{M}$ $\mathrm{KOH}$ electrolyte with an H-type electrochemical cell. A graphite rod, saturated calomel electrode (SCE), and the synthesized samples were used as the counter, reference, and working electrodes, respectively. The system was purged with Ar gas throughout the test and linear sweep voltammetry was run with a sweep rate of $2 \mathrm{mV} \mathrm{s}^{-1}$ to evaluate the catalytic activity. To minimize the effect of capacitive current originating from the $\mathrm{Ni}$ ion oxidation on the catalytic performance, LSV with reverse scan was measured for the OER performance test. The mass loading of the catalysts on the carbon fiber substrate was about $2 \mathrm{mg} \mathrm{cm}^{-2}$. All of the potentials are automatically iR-corrected and presented with respect to the reversible hydrogen electrode (RHE), which were obtained from the Nernst equation: $E_{\mathrm{RHE}}=E_{\mathrm{SCE}}+0.059$ $\mathrm{pH}+E_{\mathrm{SCE}}{ }^{\circ}$. The calibration of the SCE reference electrode is detailed in the Supporting information (Figure S8). The thermodynamic equilibrium potential for OER is $1.23 \mathrm{~V}$ vs RHE. So, the overpotential was obtained from the difference between ERHE and 1.23 V. The measurements were made three times and the average value is reported. The stability tests were carried out by the chronopotentiometry at current densities of 30,200 , and $500 \mathrm{~mA} / \mathrm{cm}^{2}$. Electrochemical impedance spectra (EIS) measurements were carried out from 0.1 to $100000 \mathrm{~Hz}$ with an amplitude of $5 \mathrm{mV}$ and an overpotential of $300 \mathrm{mV}$.

Computational Method. The structure optimization and electronic structure calculations were performed by the VASP 5.4 package, and the exchange-correlation energy functional was modeled by the Perdew-Burke-Ernzerhof functional. The performed calculations were spin-polarized and the initial magnetic moment was considered for all of the elements to ensure the accurateness of the calculations and influence of the doping effect. Three systems such as pure $\mathrm{Ni}_{5} \mathrm{P}_{4}$, top layeroxidized $\left(\mathrm{Ni}_{5}(\mathrm{P} / \mathrm{O})_{4}\right)$ and tin-doped top layer-oxidized (Sn$\left.\mathrm{Ni}_{5}(\mathrm{P} / \mathrm{O})_{4}\right)$ were considered to simulate our experimental samples which are pristine $\mathrm{Ni}_{5} \mathrm{P}_{4}$, surface oxidized $\mathrm{Ni}_{5} \mathrm{P}_{4}$ and $\mathrm{Sn}$-doped surface oxidized $\mathrm{Ni}_{5} \mathrm{P}_{4}$, respectively. Each of the calculated systems contains 144 atoms. During the structure optimization process, the plane wave cutoff energy was $520 \mathrm{eV}$ according to the advice procedure of maximum cutoff multiplied by the factor 1.3 , and $k$-points were $3 \times 3 \times 2$ for the supercell with 144 atoms. For all of the structures, the supercells were relaxed to an energy convergence of $10-4 \mathrm{eV}$. For the density of states (DOS) calculations, the increased kmesh of $6 \times 6 \times 4$ was used.

\section{ASSOCIATED CONTENT}

\section{Supporting Information}

The Supporting Information is available free of charge at https://pubs.acs.org/doi/10.1021/acscatal.1c00476.

SEM micrographs of $\mathrm{Sn}-\mathrm{Ni}_{2} \mathrm{O}_{3} \mathrm{H}$ ( $\mathrm{a}$ and $\mathrm{b}$ ) and the pristine $\mathrm{Ni}_{4} \mathrm{P}_{4}(\mathrm{c})$; the high-magnification TEM micrograph of SnNiP; SEM-EDS mapping of SnNiP; XRD patterns of $\mathrm{Sn}-\mathrm{Ni}_{2} \mathrm{O}_{3} \mathrm{H}, \mathrm{Ni}_{5} \mathrm{P}_{4}$, and $\mathrm{SnNiP}$; XRD patterns of the various doping levels; polarization curves of SnNiP; Raman spectra of SnNiP before and after the OER test; and the visual representation of the bond between the doping $\mathrm{Sn}$ element and near oxygen atom (PDF)

(PDF)

\section{AUTHOR INFORMATION}

\section{Corresponding Authors}

Tofik Ahmed Shifa - Division of Materials Science, Department of Engineering Sciences and Mathematics, Luleå University of Technology, 97187 Luleå, Sweden; (1) orcid.org/0000-0002-7411-2692;

Email: tofik.ahmed.shifa@ltu.se 
Alberto Vomiero - Division of Materials Science, Department of Engineering Sciences and Mathematics, Luleå University of Technology, 97187 Luleå, Sweden; Department of Molecular Sciences and Nanosystems, Ca' Foscari University of Venice, 30172 Venezia, Italy; 이이.org/0000-0003-2935-1165; Email: alberto.vomiero@ltu.se, alberto.vomiero@unive.it

\section{Authors}

Khabib Yusupov - Division of Materials Science, Department of Engineering Sciences and Mathematics, Luleå University of Technology, 97187 Luleå, Sweden

Getachew Solomon - Division of Materials Science, Department of Engineering Sciences and Mathematics, Luleå University of Technology, 97187 Luleå, Sweden

Alessandro Gradone - CNR-IMM Bologna Section, 40129 Bologna, Italy; Chemistry Department "Giacomo Ciamician", University of Bologna, 40126 Bologna, Italy

Raffaello Mazzaro - CNR-IMM Bologna Section, 40129 Bologna, Italy; 이이.orid.org/0000-0003-4598-9556

Elti Cattaruzza - Department of Molecular Sciences and Nanosystems, Ca' Foscari University of Venice, 30172 Venezia, Italy; ○ orcid.org/0000-0003-0643-0266

Complete contact information is available at:

https://pubs.acs.org/10.1021/acscatal.1c00476

\section{Author Contributions}

This manuscript was written through the contributions of all authors. All authors have given approval to the final version of the manuscript.

\section{Notes}

The authors declare no competing financial interest.

\section{ACKNOWLEDGMENTS}

The authors acknowledge the Kempe Foundation (JCK1505, JCK1703, and SMK1839), the Knut och Alice Wallenberg Foundation (grant number KAW 2016.346), the ÅFORSK Foundation, and the Luleå University of Technology for financial support. The authors would also like to thank NSC, Tetralith for allocation of high-performance computing time and resources (projects SNIC 2019/3-450 and SNIC 2019/3684), through the Swedish National Infrastructure for Computing (SNIC).

\section{REFERENCES}

(1) United Nations, Resolution Adopted by the General Assembly 2015, A/RES/71/1,3.Wor.

(2) Gray, H. B. Powering the Planet with Solar Fuel. Nat. Chem. 2009, 1,7

(3) Walter, M. G.; Warren, E. L.; McKone, J. R.; Boettcher, S. W.; Mi, Q.; Santori, E. A.; Lewis, N. S. Solar Water Splitting Cells. Chem. Rev. 2010, 110, 6446-6473.

(4) Shifa, T. A.; Vomiero, A. Confined Catalysis: Progress and Prospects in Energy Conversion. Adv. Energy Mater. 2019, 9, No. 1902307.

(5) Kibsgaard, J.; Chorkendorff, I. Considerations for the Scaling-up of Water Splitting Catalysts. Nat. Energy 2019, 4, 430-433.

(6) Sun, Z.; Ma, T.; Tao, H.; Fan, Q.; Han, B. Fundamentals and Challenges of Electrochemical CO2 Reduction Using Two-Dimensional Materials. Chem 2017, 3, 560-587.

(7) Liang, Z.; Lu, Y.-C. Critical Role of Redox Mediator in Suppressing Charging Instabilities of Lithium-Oxygen Batteries. J. Am. Chem. Soc. 2016, 138, 7574-7583.

(8) Suen, N.-T.; Hung, S.-F.; Quan, Q.; Zhang, N.; Xu, Y.-J.; Chen, H. M. Electrocatalysis for the Oxygen Evolution Reaction: Recent
Development and Future Perspectives. Chem. Soc. Rev. 2017, 46, 337-365.

(9) Guo, P.; Wang, Z.; Zhang, T.; Chen, C.; Chen, Y.; Liu, H.; Hua, M.; Wei, S.; Lu, X. Initiating an Efficient Electrocatalyst for Water Splitting via Valence Configuration of Cobalt-Iron Oxide. Appl. Catal., B 2019, 258, No. 117968 .

(10) Yeo, B. S.; Bell, A. T. Enhanced Activity of Gold-Supported Cobalt Oxide for the Electrochemical Evolution of Oxygen. J. Am. Chem. Soc. 2011, 133, 5587-5593.

(11) Huang, Y.; Hu, L.; Liu, R.; Hu, Y.; Xiong, T.; Qiu, W.; Balogun, M.-S.; Pan, A.; Tong, Y. Nitrogen Treatment Generates Tunable Nanohybridization of Ni5P4 Nanosheets with Nickel Hydr(Oxy)Oxides for Efficient Hydrogen Production in Alkaline, Seawater and Acidic Media. Appl. Catal., B 2019, 251, 181-194.

(12) Li, W.; Xiong, D.; Gao, X.; Liu, L. The Oxygen Evolution Reaction Enabled by Transition Metal Phosphide and Chalcogenide Pre-Catalysts with Dynamic Changes. Chem. Commun. 2019, 55, 8744-8763.

(13) Pan, Y.; Liu, Y.; Zhao, J.; Yang, K.; Liang, J.; Liu, D.; Hu, W.; Liu, D.; Liu, Y.; Liu, C. Monodispersed Nickel Phosphide Nanocrystals with Different Phases: Synthesis, Characterization and Electrocatalytic Properties for Hydrogen Evolution. J. Mater. Chem. A 2015, 3, 1656-1665.

(14) Yu, F.; Zhou, H.; Huang, Y.; Sun, J.; Qin, F.; Bao, J.; Goddard, W. A.; Chen, S.; Ren, Z. High-Performance Bifunctional Porous NonNoble Metal Phosphide Catalyst for Overall Water Splitting. Nat. Commun. 2018, 9, No. 2551.

(15) Liu, K.; Zhang, C.; Sun, Y.; Zhang, G.; Shen, X.; Zou, F.; Zhang, H.; Wu, Z.; Wegener, E. C.; Taubert, C. J.; Miller, J. T.; Peng, Z.; Zhu, Y. High-Performance Transition Metal Phosphide Alloy Catalyst for Oxygen Evolution Reaction. ACS Nano 2018, 12, 158167.

(16) Li, D.; Baydoun, H.; Kulikowski, B.; Brock, S. L. Boosting the Catalytic Performance of Iron Phosphide Nanorods for the Oxygen Evolution Reaction by Incorporation of Manganese. Chem. Mater. 2017, 29, 3048-3054.

(17) Suryanto, B. H. R.; Wang, Y.; Hocking, R. K.; Adamson, W.; Zhao, C. Overall Electrochemical Splitting of Water at the Heterogeneous Interface of Nickel and Iron Oxide. Nat. Commun. 2019, 10, No. 5599.

(18) Chatti, M.; Gardiner, J. L.; Fournier, M.; Johannessen, B.; Williams, T.; Gengenbach, T. R.; Pai, N.; Nguyen, C.; MacFarlane, D. R.; Hocking, R. K.; Simonov, A. N. Intrinsically Stable in Situ Generated Electrocatalyst for Long-Term Oxidation of Acidic Water at up to $80{ }^{\circ} \mathrm{C}$. Nat. Catal. 2019, 2, 457-465.

(19) Wang, J.; Gan, L.; Zhang, W.; Peng, Y.; Yu, H.; Yan, Q.; Xia, X.; Wang, X. In Situ Formation of Molecular Ni-Fe Active Sites on Heteroatom-Doped Graphene as a Heterogeneous Electrocatalyst toward Oxygen Evolution. Sci. Adv. 2018, 4, No. eaap7970.

(20) Ibupoto, Z. H.; Tahira, A.; Tang, P.; Liu, X.; Morante, J. R.; Fahlman, M.; Arbiol, J.; Vagin, M.; Vomiero, A. MoSx@NiO Composite Nanostructures: An Advanced Nonprecious Catalyst for Hydrogen Evolution Reaction in Alkaline Media. Adv. Funct. Mater. 2019, 29, No. 1807562.

(21) Tahira, A.; Ibupoto, Z. H.; Mazzaro, R.; You, S.; Morandi, V.; Natile, M. M.; Vagin, M.; Vomiero, A. Advanced Electrocatalysts for Hydrogen Evolution Reaction Based on Core-Shell MoS 2 / TiO 2 Nanostructures in Acidic and Alkaline Media. ACS Appl. Energy Mater. 2019, 2, 2053-2062.

(22) Solomon, G.; Mazzaro, R.; You, S.; Natile, M. M.; Morandi, V.; Concina, I.; Vomiero, A. Ag2S/MoS2 Nanocomposites Anchored on Reduced Graphene Oxide: Fast Interfacial Charge Transfer for Hydrogen Evolution Reaction. ACS Appl. Mater. Interfaces 2019, 11, 22380-22389.

(23) Mazzaro, R.; Boscolo Bibi, S.; Natali, M.; Bergamini, G.; Morandi, V.; Ceroni, P.; Vomiero, A. Hematite Nanostructures: An Old Material for a New Story. Simultaneous Photoelectrochemical Oxidation of Benzylamine and Hydrogen Production through $\mathrm{Ti}$ Doping. Nano Energy 2019, 61, 36-46. 
(24) Liu, F. Q.; Liu, J. W.; Gao, Z.; Wang, L.; Fu, X.-Z.; Yang, L. X.; Tao, Y.; Yin, W. H.; Luo, F. Constructing Bimetal-Complex Based Hydrogen-Bonded Framework for Highly Efficient Electrocatalytic Water Splitting. Appl. Catal., B 2019, 258, No. 117973.

(25) Liu, K.; Wang, F.; He, P.; Shifa, T. A.; Wang, Z.; Cheng, Z.; Zhan, X.; He, J. The Role of Active Oxide Species for Electrochemical Water Oxidation on the Surface of 3d-Metal Phosphides. Adv. Energy Mater. 2018, 8, No. 1703290.

(26) Li, Y.; Zhang, H.; Jiang, M.; Zhang, Q.; He, P.; Sun, X. 3D SelfSupported Fe-Doped Ni2P Nanosheet Arrays as Bifunctional Catalysts for Overall Water Splitting. Adv. Funct. Mater. 2017, 27, No. 1702513.

(27) Cai, L.; Qiu, B.; Lin, Z.; Wang, Y.; Ma, S.; Wang, M.; Tsang, Y. H.; Chai, Y. Active Site Engineering of Fe- and Ni-Sites for Highly Efficient Electrochemical Overall Water Splitting. J. Mater. Chem. A 2018, 6, 21445-21451.

(28) Liang, H.; N. Gandi, A.; H. Anjum, D.; Wang, X.; Schwingenschlögl, U.; N. Alshareef, H. Plasma-Assisted Synthesis of $\mathrm{NiCoP}$ for Efficient Overall Water Splitting. Nano Lett. 2016, 16, $7718-7725$

(29) Zheng, X.; Zhang, B.; De Luna, P.; Liang, Y.; Comin, R.; Voznyy, O.; Han, L.; García de Arquer, F. P.; Liu, M.; Dinh, C. T.; Regier, T.; Dynes, J. J.; He, S.; Xin, H. L.; Peng, H.; Prendergast, D.; $\mathrm{Du}, \mathrm{X}$.; Sargent, E. H. Theory-Driven Design of High-Valence Metal Sites for Water Oxidation Confirmed Using in Situ Soft X-Ray Absorption. Nat. Chem. 2018, 10, 149-154.

(30) Du, C.; Yang, L.; Yang, F.; Cheng, G.; Luo, W. Nest-like NiCoP for Highly Efficient Overall Water Splitting. ACS Catal. 2017, 7, 4131-4137.

(31) Lin, Y.; Pan, Y.; Liu, S.; Sun, K.; Cheng, Y.; Liu, M.; Wang, Z.; $\mathrm{Li}$, X.; Zhang, J. Construction of Multi-Dimensional Core/Shell Ni/ NiCoP Nano-Heterojunction for Efficient Electrocatalytic Water Splitting. Appl. Catal., B 2019, 259, No. 118039.

(32) Xu, J.; Sousa, J. P.; Mordvinova, N. E.; Costa, J. D.; Petrovykh, D. Y.; Kovnir, K.; Lebedev, O. I.; Kolen'ko, Y. V. Al-Induced In Situ Formation of Highly Active Nanostructured Water-Oxidation Electrocatalyst Based on Ni-Phosphide. ACS Catal. 2018, 8, 25952600.

(33) He, Q.; Tian, D.; Jiang, H.; Cao, D.; Wei, S.; Liu, D.; Song, P.; Lin, Y.; Song, L. Achieving Efficient Alkaline Hydrogen Evolution Reaction over a Ni5P4 Catalyst Incorporating Single-Atomic RuSites. Adv. Mater. 2020, 32, No. 1906972.

(34) Feaster, J. T.; Shi, C.; R. Cave, E.; Hatsukade, T.; N. Abram, D.; P. Kuhl, K.; Hahn, C.; K. Nørskov, J.; F. Jaramillo, T. Understanding Selectivity for the Electrochemical Reduction of Carbon Dioxide to Formic Acid and Carbon Monoxide on Metal Electrodes. ACS Catal. 2017, 7, 4822-4827.

(35) Dutta, A.; Rahaman, M.; C. Luedi, N.; Mohos, M.; Broekmann, P. Morphology Matters: Tuning the Product Distribution of $\mathrm{CO} 2$ Electroreduction on Oxide-Derived Cu Foam Catalysts. ACS Catal. 2016, 6, 3804-3814.

(36) Ling, Y.; Wang, G.; Wheeler, D. A.; Zhang, J. Z.; Li, Y. SnDoped Hematite Nanostructures for Photoelectrochemical Water Splitting. Nano Lett. 2011, 11, 2119-2125.

(37) Sun, L.; Han, C.; Zhang, T.; Zhu, H.; Xia, X.; Li, L. $\mathrm{CoOx}(\mathrm{OH}) 2(1-\mathrm{x})$ Doped with Sn Urchin-like Spheres for Enhanced Oxygen Evolution Reaction. Mater. Sci. Semicond. Process. 2020, 110, No. 104935.

(38) Debata, S.; Banerjee, S.; Chakraborty, S.; Sharma, P. K. Template Assisted Hydrothermal Synthesis of CoSnO3 Hollow Microspheres for Electrocatalytic Oxygen Evolution Reaction. Int. J. Hydrogen Energy 2019, 44, 21623-21636.

(39) Kim, N.-I.; Sa, Y. J.; Cho, S.-H.; So, I.; Kwon, K.; Joo, S. H.; Park, J.-Y. Enhancing Activity and Stability of Cobalt Oxide Electrocatalysts for the Oxygen Evolution Reaction via Transition Metal Doping. J. Electrochem. Soc. 2016, 163, F3020-F3028.

(40) Uelzen, T.; Müller, J. Wettability Enhancement by Rough Surfaces Generated by Thin Film Technology. Thin Solid Films 2003, 434, 311-315.
(41) Zhou, Q.; Chen, Y.; Zhao, G.; Lin, Y.; Yu, Z.; Xu, X.; Wang, X.; Liu, H. K.; Sun, W.; Dou, S. X. Active-Site-Enriched Iron-Doped Nickel/Cobalt Hydroxide Nanosheets for Enhanced Oxygen Evolution Reaction. ACS Catal. 2018, 8, 5382-5390.

(42) Fabbri, E.; Habereder, A.; Waltar, K.; Kötz, R.; Schmidt, T. J. Developments and Perspectives of Oxide-Based Catalysts for the Oxygen Evolution Reaction. Catal. Sci. Technol. 2014, 4, 3800-3821.

(43) Xu, X.; Song, F.; Hu, X. A Nickel Iron Diselenide-Derived Efficient Oxygen-Evolution Catalyst. Nat. Commun. 2016, 7, No. 12324.

(44) Zhou, H.; Yu, F.; Sun, J.; He, R.; Chen, S.; Chu, C.-W.; Ren, Z. Highly Active Catalyst Derived from a 3D Foam of Fe(PO3)2/Ni2P for Extremely Efficient Water Oxidation. Proc. Natl. Acad. Sci. U. S. A. 2017, 114, 5607-5611.

(45) Tang, C.; Zhang, R.; Lu, W.; He, L.; Jiang, X.; Asiri, A. M.; Sun, X. Fe-Doped CoP Nanoarray: A Monolithic Multifunctional Catalyst for Highly Efficient Hydrogen Generation. Adv. Mater. 2017, 29, No. 1602441.

(46) Li, J.; Yan, M.; Zhou, X.; Huang, Z.-Q.; Xia, Z.; Chang, C.-R.; Ma, Y.; Qu, Y. Mechanistic Insights on Ternary Ni2-XCoxP for Hydrogen Evolution and Their Hybrids with Graphene as Highly Efficient and Robust Catalysts for Overall Water Splitting. Adv. Funct. Mater. 2016, 26, 6785-6796.

(47) Qiu, B.; Cai, L.; Wang, Y.; Lin, Z.; Zuo, Y.; Wang, M.; Chai, Y. Fabrication of Nickel-Cobalt Bimetal Phosphide Nanocages for Enhanced Oxygen Evolution Catalysis. Adv. Funct. Mater. 2018, 28, No. 1706008.

(48) Zhang, R.; Tang, C.; Kong, R.; Du, G.; Asiri, A. M.; Chen, L.; Sun, X. Al-Doped CoP Nanoarray: A Durable Water-Splitting Electrocatalyst with Superhigh Activity. Nanoscale 2017, 9, 47934800.

(49) He, P.; Yu, X.-Y.; Lou, X. W. D. Carbon-Incorporated NickelCobalt Mixed Metal Phosphide Nanoboxes with Enhanced Electrocatalytic Activity for Oxygen Evolution. Angew. Chem., Int. Ed. 2017, 56, 3897-3900.

(50) Seh, Z. W.; Kibsgaard, J.; Dickens, C. F.; Chorkendorff, I.; Nørskov, J. K.; Jaramillo, T. F. Combining Theory and Experiment in Electrocatalysis: Insights into Materials Design. Science 2017, 355, No. eaad4998.

(51) Ledendecker, M.; Krick Calderón, S.; Papp, C.; Steinrück, H.P.; Antonietti, M.; Shalom, M. The Synthesis of Nanostructured Ni5P4 Films and Their Use as a Non-Noble Bifunctional Electrocatalyst for Full Water Splitting. Angew. Chem., Int. Ed. 2015, 54, 12361-12365.

(52) Wahl, S.; El-Refaei, S. M.; Buzanich, A. G.; Amsalem, P.; Lee, K.-S.; Koch, N.; Doublet, M.-L.; Pinna, N. Zn0.35Co0.65O - A Stable and Highly Active Oxygen Evolution Catalyst Formed by Zinc Leaching and Tetrahedral Coordinated Cobalt in Wurtzite Structure. Adv. Energy Mater. 2019, 9, No. 1900328.

(53) Biesinger, M. C.; Payne, B. P.; Lau, L. W. M.; Gerson, A.; Smart, R. S. C. X-Ray Photoelectron Spectroscopic Chemical State Quantification of Mixed Nickel Metal, Oxide and Hydroxide Systems. Surf. Interface Anal. 2009, 41, 324-332.

(54) Li, Q.; Fu, J.; Zhu, W.; Chen, Z.; Shen, B.; Wu, L.; Xi, Z.; Wang, T.; Lu, G.; Zhu, J.; Sun, S. Tuning Sn-Catalysis for Electrochemical Reduction of $\mathrm{CO} 2$ to $\mathrm{CO}$ via the Core/Shell $\mathrm{Cu}$ / SnO2 Structure. J. Am. Chem. Soc. 2017, 139, 4290-4293.

(55) Song, L. X.; Yang, Z. K.; Teng, Y.; Xia, J.; Du, P. Nickel Oxide Nanoflowers: Formation, Structure, Magnetic Property and Adsorptive Performance towards Organic Dyes and Heavy Metal Ions. J. Mater. Chem. A 2013, 1, 8731-8736.

(56) Purushothaman, K. K.; Manohara Babu, I.; Sethuraman, B.; Muralidharan, G. Nanosheet-Assembled NiO Microstructures for High-Performance Supercapacitors. ACS Appl. Mater. Interfaces 2013, 5, 10767-10773.

(57) Chen, W.; Wang, H.; Li, Y.; Liu, Y.; Sun, J.; Lee, S.; Lee, J.-S.; Cui, Y. In Situ Electrochemical Oxidation Tuning of Transition Metal Disulfides to Oxides for Enhanced Water Oxidation. ACS Cent. Sci. 2015, 1, 244-251. 
(58) Dutta, A.; Pradhan, N. Developments of Metal Phosphides as Efficient OER Precatalysts. J. Phys. Chem. Lett. 2017, 8, 144-152. 